This is the final peer-reviewed accepted manuscript of:

Ugolini, C., Bruni, M. L., Mammi, I., Donatini, A., \& Fiorentini, G. (2016). Dealing with minor illnesses: the link between primary care characteristics and Walk-in Centres' attendances. Health Policy, 120(1), 72-80.

The final published version is available online at: https://doi.org/10.1016/i.healthpol.2015.10.009

Rights / License:

The terms and conditions for the reuse of this version of the manuscript are specified in the publishing policy. For all terms of use and more information see the publisher's website. 


\title{
Dealing with minor illnesses: the link between primary care characteristics and Walk-in Centres' attendances
}

\author{
Andrea Donatini*, Gianluca Fiorentini**, \\ Matteo Lippi Bruni**, Irene Mammi**, Cristina Ugolini** \\ * Health Department of Emilia-Romagna - Italy \\ ** Department of Economics, University of Bologna, Italy
}

\begin{abstract}
The reformulation of existing boundaries between primary and secondary care, in order to shift selected services traditionally provided by Emergency Departments to community-based alternatives, has determined a variety of organisational solutions. One innovative change has been the introduction of fast-track systems for minor injuries or illnesses, whereby community care providers are involved in order to divert patients away from EDs. These facilities offer an openaccess service for patients not requiring hospital treatments, and may be staffed by nurses and/or primary care general practitioners operating within, or alongside, the ED. To date little research has been undertaken on such experiences. To fill this gap, we analyse a Walk-in Centre (Wic) in the Italian city of Parma, consisting of a minor injury unit located alongside the teaching hospital's ED. We examine the link between the utilisation rates of the WiC and primary care characteristics, focusing on the main organisational features of the practices and estimating panel count data models for 2007-2010. Our main findings indicate that the extension of practice opening hours significantly lowers the number of attendances, after controlling for General Practitioner's and practice's characteristics.
\end{abstract}

\section{Highlights}

- We investigate the determinants of attendance to an Italian Walk-in centre.

- We focus on the link between primary care characteristics and WiC's utilisation.

- We estimate panel count data models for the period 2007-2010.

- The extension of GP's office hours reduces significantly the number of attendances.

Key words: Walk-in Centres, avoidable attendance, primary care, panel count data models.

JEL classification: I11, I18, C31 


\section{Introduction}

A reorganisation of the boundaries between primary and secondary care to shift services traditionally supplied by hospitals to community-based providers, has attracted increasing interest from policymakers. This is of particular relevance for Emergency Departments (EDs), which are frequently required to deal with patients best treated in a primary care setting.

Patients inappropriately seeking care at the ED are sometimes referred to as "primary care attenders" [1], since they use hospital ED services instead of ambulatory care centres, despite the fact that the latter would represent a more natural setting for treating non-severe conditions. Several countries have introduced solutions to tackle the problem, which either involve community care (for example, through the extension of practices' opening hours, the organisation of out-of-hours work or primary care-based emergency services [2,3]), or which are organized and financed by the hospitals themselves. Most of these initiatives have established centres to manage fast-track systems for minor illnesses aimed at reducing the number of primary care attenders and have adopted heterogeneous organisational and operational arrangements for this scope. As there is no standard definition for these centres, henceforth we shall refer as Walk-in Centres (WiCs) to any arrangement for treating minor injuries and illnesses with no requirement for patients to prebook an appointment or to be registered at the centre or with any practice, irrespectively of whether they are organised as separate centres or located within a hospital.

The literature on WiCs has sought, in the first place, to assess the impact of these initiatives on the use of emergency services since these programs, although set up in differing institutional settings, arise from the common purpose to curb the rising number of primary care attenders. In this context a largely unexplored issue is the analysis of the links between the organisation of primary care services and patients' flows to WiCs, together with the determinants of such flows. This is precisely the focus of the present paper. In particular, we analyse the determinants of patients' utilisation of a primary care-based emergency service located in Parma (Italy): it is a WiC located alongside the University Hospital's ED, financed by the Local Health Authority (LHA).

Our line of investigation is especially relevant for the Italian institutional context, since the design and organisation of primary care in the Italian NHS is aimed at ensuring a comprehensive response to cases of minor illnesses. By identifying the main factors accounting for the high utilisation of WiCs, we can evaluate which characteristics of the practice contribute to increasing/decreasing the number of visits to the WiC the most, and which General Practitioners (GPs) have a relatively higher probability of recording a large number of WiC attendances given their personal and list 
characteristics. A better understanding of the determinants of WiC flow patterns will help policymakers improve the organisation of the practice based system in order to ensure an effective response to patients' demand and to target groups identified as primary care attenders.

Our contribution is threefold. Firstly, we examine a pilot experience for Italy, an institutional setting where the different levels of care interact to ensure access to public services, and where their multifaceted financing mechanisms affect providers' incentives and patients' utilisation patterns. The design of a balanced organisation of first aid services through the integration of primary, community and secondary care, represents a key target capable of improving the appropriateness of treatment. This aims at reconciling the strict public budget constraints, with the need to ensure universal access to healthcare services that are (almost) free at the point of demand. Secondly, we fill a gap in the literature by examining the link between the utilisation of WiCs and the primary care system, considering GPs', patients' and organisational characteristics of the practices. This allows to establish which features contribute the most towards diverting demand away from GPs and in the direction of more intensive settings such as WiCs. This information is intended to support the design of effective policies for achieving a more appropriate utilisation of primary care. We also extend our analysis by taking into account the influence on WiC attendances of the utilisation of ED wards which represent the natural alternative to the WiC when patients choose not to seek care from GPs. This result should not be interpreted as an evidence of the impact produced by the WiC on the use of the local ED but as the attempt to assess whether a GP's practice with a more intensive use of WiCs is also correlated to an intense utilisation of hospital EDs and to what extent the two sources act as substitutes. Thirdly, in the final section we disentangle our main results by investigating the distribution of visits across times of the day and the age composition of the users, in order to provide a deeper analysis of the determinants of WiC visits according to different types of attenders.

\section{The Walk-in Centre initiatives}

WiCs widen the choice available to patients affected by minor health problems. The net effect on patients' flows of increased choice is a matter of empirical concern. In fact, WiCs may substitute for other providers but they may also increase overall demand, as a result of additional services (for patients who in their absence would have managed the problem themselves) or duplicative ones (if patients attend the WiC after or before referring to their GP) being provided. More in general, the introduction of WiCs affects demand for care on dimensions such as quality, time, appropriateness, access, equity and costs of the treatments. Partly as a consequence of their 
heterogeneous nature, the findings on the volume and composition of the services provided by WiCs and on the impact on the patients' use of primary care and ED centres are far still inconclusive. Moreover, such conclusions are not easily generalizable across Countries so as to draw clear-cut policy recommendations based on best practices. A further limitation in the literature, that mainly concentrates on evaluating the capacity of WiCs to reduce ED overcrowding, is the lack of attention to the link between the WiC utilisation and the organisation of GP services.

Experiences developing alternative care pathways for minor conditions are well established in countries, such as Australia, Canada, and the USA, where these centres have operated since the early 1970s [3]. However, among the government-funded health systems, the case of the UK has stirred an intense debate and it is of particular relevance for our work because of the similarities the British and Italian National Health Service (NHS) [4].

In the UK, the first wave of interventions consisted on telephone-based services through which nurses were expected to properly support patients' self-referrals. Since the year 2000, new initiatives contributed to the establishment of WiCs as an alternative to both GP and ED referrals [5]. Between 2000 to 2010 more than 230 WiCs were started with the later addition of $150 \mathrm{GP}$-led health centres --to provide care between 8am and 8pm, 7 days a week [6]. Empirical studies show no significant impact of these arrangements on ED attendances and on other providers such as the GPs [7], with the only exception of Arain et al. [8] that displays a significant decline in ED attendances. Therefore the improvements in the appropriateness of patients' flow appear negligible. As for patients' satisfaction, such facilities are greatly appreciated by patients, although their effectiveness appears mixed $[1,4,7-10]$, especially in terms of the threat to the continuity of primary care that such facilities could pose [11], and of the duplication of services when patients use them during their GP's office hours $[12,13]$.

The paper whose research question more closely reflects ours is Salisbury et al. [14] that uses questionnaires to study the characteristics of patients treated at British WiCs. WiC users are of high socio-economic status, mainly young adults, with an higher proportion of man aged 17 to 45 years and women aged 17 to 35 years, the vast majority registered with a GP and who lived locally in the area. The authors conclude recognising that WiCs appear to improve access to care for individuals that are not "necessarily those with the greatest health needs".

In Italy these experiences are quite new and, to the best of our knowledge, the literature lacks of evidence about their features and effectiveness. An exception is the recent work by Buia et al. [15] 
who use administrative data referred to an out-of-hours service in the Veneto Region to describe the characteristics of patients admitted and of the services demanded.

\section{A primary care-based emergency service in Italy: the Walk-in Centre in Parma}

Italy has a regionally-based National Health Service (NHS) where central government establishes a national statutory benefits package, and where Regions provide health services through their LHAs $[16,17]$. Primary care services are delivered by independent contractors with the NHS and are free of charge at the point of need. Registration with a family physician is compulsory, and each physician has a maximum of 1500 registered patients.

Over the last decade there has been increasing interest in improving the organisation of primary care, by addressing its quality [18], and in reducing the numbers of referrals to EDs for non-severe conditions [19]. Important organisational changes have been implemented in primary care, which include initiatives designed to promote the extension of opening hours and out-of-hours care by GP groups, or to establish primary care centres able to provide a more comprehensive range of acute and chronic medical care, and Walk-in-Centres inside or near to hospitals. However, there is still little evidence of the impact that such interventions have had so far.

The present study focuses on an experience in the Italian city of Parma, situated in the centrenorth of Italy. Parma LHA is subdivided into four Health Districts, each responsible for providing primary care, non-hospital-based specialist medicine, residential and semi-residential care. The largest Health District covers the entire municipality of Parma, and delivers primary care to approximately 217,000 people through around 150 GPs, most of whom work in associated practices where GPs coordinate their activities, for example by replacing one another in cases of absence, share the same premise, and if present, the same nursing staff [20 - 22]. The purpose of this is also to ensure the mutual sharing of planning strategies and guidelines. Moreover, the Parma LHA provides those GPs already working in associated practices with additional remuneration if they arrange their opening hours in such a way as to ensure an overall daily coverage exceeding the minimum contractual standard of 6 hours and up to a maximum of 12 hours. This policy is designed to ensure that patients can access primary care services conveniently, thus reducing the likelihood of $\mathrm{WiC}$ and $\mathrm{ED}$ attendances determined by the absence of primary care services right throughout the day.

In 2003 Parma LHA set up a WiC nearby the hospital staffed by primary care or deputised physicians, who are employed by the LHA. The WiC is open daily from 8 a.m. to 8 p.m., and treats 
non-severe conditions that cannot be deferred for a further $24 / 48$ hours. Care is provided by a team of eight clinicians supported by a nurse. Patients can freely and directly access the WiC, either as an alternative to a visit to their GP, or outside of surgery hours, or they can be redirected there by the ED's front desk that has triaged the patient as non-urgent ("triage out"). Admission to University Hospital for further specialist examination is allowed, should the clinician diagnose an acute, urgent condition. As the WiC's catchment area is the Parma district, and all GP's premises are located within the same municipality, geographical distance does not constitute a relevant barrier to accessibility.

Table 1 summarises the WiC's activity between 2007-2010: the yearly number of visits is constantly around 24,000; $43 \%$ of patients used the clinic from $8 \mathrm{am}$ to $12 \mathrm{am}, 28 \%$ between $12 \mathrm{am}$ and 4 pm, and 29\% after 4 pm. Children and elderly people were less likely to attend the clinic, while students and workers accounted for $76 \%-80 \%$ of total attendances.

\section{TABLE 1}

The most common diagnosis was HEENT (head, eye, ear, nose, throat), 35\%-39\% of cases being accounted for by eye problems, and $13 \%-17 \%$ of cases for ear, nose and throat problems. The remaining diagnoses included skin problems (9-12\%) and insects bites and injuries (3-4\%), whereas chronic conditions were infrequent.

\section{Identifying the main drivers of utilisation}

\subsection{The data}

We exploit datasets provided by the regional Department of Health, merging data on annual WiC and ED attendances, with information regarding the characteristics of GPs and their practices, by means of a GP identifier. As WiC attendances are aggregated at the GP level, and we observe the number of accesses by patients registered on each list, the unit of observation is the GP. The estimating sample includes all the GPs operating in the Parma Health District over the 4-year period 2007-2010. Our main objective is to investigate the determinants of the utilisation of the WiC, with a specific focus on the importance of the organisational features of primary care practices, once the characteristics of GPs and their registered patients have been accounted for.

\subsection{The econometric strategy}

We estimate an exponential conditional mean model for the count of WiC visits per GP list. Due to the evidence of over-dispersion in the data (the variance of the dependent variable is about 17 
times the mean), we choose a Negative Binomial (NB) model to get consistent estimates of the parameters of interest.

Count models for panel data allow for time-invariant, individual-specific effects that enter the conditional mean equation multiplicatively [23]. The individual effects can be assumed to be either independent of the regressors, or correlated with them: alternative model specifications depend on such assumptions. In the random effect (RE) NB model, the individual effects are assumed to be uncorrelated with the covariates; on the contrary, the fixed effect (FE) model allows for a correlation between the individual effects and the regressors.

The choice between RE and FE models is not straightforward. RE estimators are more appropriate and are efficient when the sample is drawn from a larger population about which the researcher wants to do inference; the FE estimators are instead a natural choice when the data constitute a complete sample and the aim is to draw conclusions for that specific group of observations [23; 24]. Consequently the choice depends on the objectives of the analysis. Our sample consists of all the GPs working in the district of Parma whose patients have the access to the WiC as a viable option. Since we deal with the whole population of GPs affected by the initiative, the FE model seems more appropriate in this context. With respect to formal statistical testing, once both FE and RE models have been estimated, the preferred specification can be chosen on the basis of the Hausman test [25].

The estimating FE NB model for WiC attendances is the following:

$$
W i C_{i t}=\exp \left(\ln (\text { list size })+\ln \left(\eta_{i}\right)+\mathbf{x}^{\prime}{ }_{\mathrm{it}} \boldsymbol{\beta}+\varepsilon_{\mathrm{it}}\right)
$$

where $\mathrm{WiC}_{\mathrm{it}}$ is the number of visits to the WiC by patients registered with GP $i$ in year $t ; \mathbf{x}$ is a vector of control variables, $\eta_{i}$ is the individual effect potentially correlated with the variables in $\mathbf{x}$, and $\varepsilon_{i t}$ is the idiosyncratic error. The list size is the exposure variable in the model, such that the coefficient of $\ln$ (list size) is constrained to be equal to 1 .

We estimate the model in (1) as a conditional fixed-effect NB model by Maximum Likelihood, as proposed in [26]: this approach is the one most commonly followed in the empirical literature for NB FE estimation [27].

It has been shown that the Conditional FE NB is not a true FE estimator, as it only removes timeinvariant regressors under a very specific functional form for the $\eta_{i}[28]$. Therefore, differently from the standard FE estimators, in general it permits estimation of the parameters of the timeinvariant regressors [29]. It is generally difficult to obtain consistent estimates for the parameters in FE models when the panel is short and the high number of individual effects raise an incidental 
parameter problem. In a non-linear context, one of the few exceptions to this problem occurs when the individual-specific effects enter the model multiplicatively, as in the panel NB specification. It has been shown that, given it peculiar structure, the FE NB model does not suffer the incidental parameter problem in short panels, and the consistency of the estimates is not significantly affected by the short time dimension $[23 ; 30]$.

\subsection{Covariates}

The regressors included in vector $\mathbf{x}$ are listed in Table 2, which also provides a definition and descriptive statistics of each variable. The controls can be grouped into: (a) GP characteristics (GP male, GP seniority), (b) practice characteristics (GP with coordination responsibilities, associated GP, Nursing staff, Extended opening, adherence to local programs), (c) list characteristics (Age groups in the list; Male patients, Foreign patients), (d) utilisation of emergency healthcare services (ED visits).

TABLE 2

As regards practice's characteristics, we take into account whether the GP assumes responsibilities in coordinating activities or programs at local level, whether the practice avails itself of nursing staff, and whether the GP belongs to a group practice, thus distinguishing between individual and associated practices. We add also control dummies: one for GPs who coordinate the extension of practice opening hours in order to provide daily coverage of up to 10-12 hours, and one for GPs' participation in local disease-management programmes promoting cooperative measures and compliance with clinical guidelines. In order to improve the robustness of the estimates and to obtain a more parsimonious model, we include in our main model only the covariates that come out as statistically significant at the $10 \%$ level in univariate regressions of the outcome variable on each of the regressors in Table 2.

All the analyses are performed using the statistical software STATA 13; the FE model is estimated by ML using the xtnbreg, fe command.

\subsection{Limitations and extensions}

Given the nature of the available data, the study suffers also from important limitations. As the response variable is measured at the practice level, we are not able to analyse the determinants of a patient's risk of referring to the WiC. Not to incur an ecological fallacy by inferring conclusions about individuals' behaviour from aggregated data [31, 32], the results have to be interpreted in terms of risk of admissions at the GP's list level. 
To deepen our understanding of the phenomenon of interest, we also exploit a more detailed disaggregation of the data on patients' visits to the WiC still measured at the GP's list level. In fact, we use information about the count of the accesses per GP by age-class of WiC attenders and time of the day, according to the ranges presented in Table 1.

We estimate the same model as in equation (1), including only the regressors significant at the $10 \%$ level in univariate regressions, but where the dependent variable is now $\mathrm{WiC}_{\mathrm{jit}}$, namely the count of WiC visits for GP $i$ at time $t$ either in the $j^{\text {th }}$ time of the day or by patients in the $j^{\text {th }}$ ageclass. The descriptives for the $\mathrm{WiC}_{\mathrm{jit}}$ variables are reported in Table 1 . When the dependent variable is the count of visits at a given time of the day, the exposure is the size of the list; when the outcome is the count of visits by patients in a given age-class, the exposure is instead the number of patients in that age class in the GP list. We are thus able to test whether practice characteristics affect differently the rates of admission by time of the day or age class. By doing so we will be able to assess whether given practice and list characteristics such as the extended opening, are good predictors of the expected count of accesses in a specific moment of the day.

\section{Empirical results}

The first part of Table 3 presents estimates for equation (1), where the number of admissions to the $\mathrm{WiC}$ is regressed against the control variables that come out as significant at the $10 \%$ level in univariate regressions; list size is included as an offset variable. In the table, we only report FE estimates as the Hausman test indicates that preference should be given to the FE specification. As discussed above, also the purpose of our work and the nature of the data support this choice.

Overall, the Incident Rate Ratios (IRRs) indicate that even when statistically significant, the magnitude of the estimated impact of our covariates is of a modest entity. GP seniority significantly affects the probability of visits to the WiC by registered patients. As for list characteristics, the share of foreign patients significantly reduces the expected utilisation of the WiC. To evaluate the influence of age composition, we take patients aged 75 or over as the reference category. The only robust statistical difference emerges when we consider the youngest age class which positively affects the utilisation of WiC services. The aggregate nature of the data prevents us from straightforwardly concluding that younger people use fast-track channels more than older individuals do. Nevertheless, this evidence is consistent with the idea that the higher opportunity cost of time to the younger group encourages them to skip the longer waiting times 
often associated to GP visits. The estimates include also year dummies and we find no evidence of marked changes in utilisation patterns over time.

TABLE 3

For an evaluation of the influence of primary care policies on the use of the WiC, it is particularly important to consider the impact of practices' organisational features. Although working in association does not affect the use of WiC, GPs whose association has agreed to coordinate opening hours to ensure daily coverage of up to 10-12 hours, record a significantly lower utilisation of the WiC. Our findings confirm that for non-severe conditions, an increased accessibility to GP services during the daytime helps significantly reduce the demand for WiCs.

As patients may seek care for minor conditions not only from their GP or from the WiC, but also from the ED, it is also interesting to examine to what extent substitution patterns across these alternative sources of treatments affect WiC utilisation. Unfortunately, we have no data on the actual utilisation of GP services by patients; however, by matching information from hospital registers with databases on primary care, it is possible to include information on ED utilisation rates by patients registered with each GP operating within the Parma District. The second part of Table 3 provides the FE estimates for equation (1), where the number of visits to the local ED not followed by hospitalisation is now included as an additional control variable. The new specification allows to evaluate the substitutability/complementarity between WiCs and EDs, a crucial issue from a policy perspective. Moreover, as regards the robustness of the other estimated effects, EDs utilisation may capture (part of) the unobserved heterogeneity associated with health care demand for non-severe conditions that bypasses the general practitioner. Such heterogeneity may stem from the different practice styles of GPs, or the idiosyncratic behaviour of patients, characterized by a diverse propensity towards using hospital or community-based services. From this perspective, it is important to evaluate whether the estimated impact of our set of controls is robust to the inclusion of ED attendances, as this allows us to assess whether, and to what extent, these unobserved factors may have influenced previous results.

We find that ED visits are negatively associated with WiC attendance. Although the impact is significant, the magnitude of the estimated effect is extremely modest, and suggests that the degree of substitution between ED and WiC is limited, at least when measured at list level.

As for the other variables, the results closely reflect the findings previously discussed. They confirm that the organisational features of the practice are more important than the GP's characteristics in determining WiC utilisation. In particular, patients enrolled with GPs who belong 
to groups extending surgery opening hours, display lower WiC utilisation rates even after controlling for access to emergency wards. The estimated reduction in the probability of WiC visits for practices that extend their opening hours amounts to around $8 \%$. The results are in line with previous estimates also for age groups and for the share of foreign patients: a high proportion of patients aged 15-44 in the list is associated with a significantly higher use of the WiC, while the opposite holds for the share of foreigners.

\section{TABLES 4 - 5}

Table 4 presents the results using WiC visits for times of the day, including, as before, only the control variables significant at the $10 \%$ level in univariate regressions. The extended opening hours of GP's practice significantly contain attendances between 8-12 am, the window with the higher turnout. The magnitude of the estimated reduction is of about $14 \%$, whereas there is no significant impact in the rest of the day. As regard users' age composition, Table 5 displays results obtained only for the two younger age classes (15-44 and 45-65) as our control variables do not produce any significant effect on WiC accesses of patients aged more than 65. For the younger patients, who are the most frequent users of $\mathrm{WiC}$, the probability to attend the $\mathrm{WiC}$ is lower when their GP proves to be relatively young, takes up responsibilities to coordinate local activities or projects, works in associated practices and is flexible in offering extended opening hours.

\section{Conclusions}

We have examined the link between attendance of a Walk-in Centre for minor illnesses located in the district of Parma (Italy), and the main characteristics of the local primary care system. We considered the case of a medium-sized Italian city where a WiC financed by the Local Health Authority was opened near to the local University Hospital. The targeted users are individuals who, suffering from minor conditions, do not seek care from their GP, and would otherwise selfrefer to the hospital's Emergency Department, an event which would increase the cost of treatment and contribute towards hospital overcrowding.

Our study aims at identifying the main determinants of the WiC's utilisation in relation to the organisation of primary care. Taking the GP as our unit of observation, we have first estimated panel count data models considering the number of visits to the WiC by patients registered with each GP operating in the District, as our dependent variable. We have then considered as dependent variable also WiC visits by time of the day and age class of the users. Our findings suggest that the GP's individual characteristics do not significantly affect attendance rates. From a 
policy perspective, the most relevant finding concerns the extension of practice opening hours: GPs offering longer opening hours record a significantly lower number of visits to the WiC in each specification. This finding suggests that extended accessibility to primary care services actually reduces self-referrals to the $\mathrm{WiC}$, with an estimated reduction in attendance probability of around $8 \%$.

Other features, such as the presence of nursing staff or the GP acting as coordinator, only affect attendance rates in certain specifications, and often only to a weakly significant effect. Furthermore, the results are robust to the introduction of ED attendance rates as a control variable. We find evidence of a statistically significant substitution effect between the WiC and the ED, although its magnitude is modest when measured at list level. As for list characteristics, we identify the age class of patients below 44 as the most influential factor. Having a large share of these individuals in the list increases the expected number of WiC visits, although the aggregated nature of our data do not allow to directly classify this group as heavy WiC users. Still, our study suggests that the behaviour of the younger age classes are more responsive to the organisation of primary care than the older groups and they can be targeted by strategies that improve flexibility of GP activity.

The literature that analyses the British WiCs' experience has highlighted that WiCs may substitute for GPs but they may also generate an increase in the overall demand for assistance by patients with minor conditions and reduce the share of such patients actually finding responses at the GP level. This increased choice may potentially threat continuity of care and duplicate services when patients use the WiC during their GP's office hours. Overall, our findings confirm the importance for policymakers of identifying those features of the organisation of primary care that make the greatest contribution to ensuring the effectiveness of GPs' gatekeeping role. A greater access to GP services during the day time could be an important means to ensure that patients affected by minor conditions seek responses in low-intensity settings such as their primary-care practices. Conversely, a greater access to GP services could also be able to reduce patients' self-referral to fast track systems such as the WiCs.

The main policy implications of the work relate to the effectiveness of the initiatives designed for improving scope and availability of primary care. In our analysis they seem able to limit the number of patients with minor injuries seeking care in alternative settings such as the WiC. According to our findings, strengthening primary care can be achieved by extending the opening hours of GPs practice which acts as an alternative to WiCs to provide primary and urgent care without appointment. This suggests the importance of assessing whether extending the 
accessibility to GP services represents a more appropriate and cost-saving alternative to the WiC for addressing minor conditions. Furthermore, one may cast doubts on the opportunity to have both policies coexisting in the same context as their objectives partially overlap.

In conclusion, our study can be seen as the first step of a research agenda that should aim at providing a detailed comparison of alternative policies for treating minor illnesses and injuries. In particular, it would be of major interest to evaluate the relative (cost) effectiveness in improving appropriateness of care of investments aimed at promoting a better accessibility to GPs vis-à-vis the opening of further WiCs.

\section{Acknowledgements}

This paper is part of the research project "The role of economic incentives in the governance of primary care" financed by the Health Department of the Emilia-Romagna region, Italy, which also provided the data. The work reflects the authors' opinions only, and does not involve the abovementioned institution. We would like to thank Antonio Brambilla and Eleonora Verdini of the Health Department for their support and the participants at the Italian Health Economics Association Conference held in Trento in November 2013 for their useful suggestions. The other usual disclaimers apply. 


\section{References}

[1] Cooke M, Fisher J, Dale J, McLeod E, Szczepura A, Walley P et al. Reducing Attendances and Waits in Emergency Departments. A systematic review of present innovations. Report to the National Co-ordinating Centre for NHS Service Delivery and Organisation R\&D (NCCSDO), 2004.

[2] Roberts E, Mays N. Can primary care and community-based models of emergency care substitute for the hospital A\&E department? Health Policy 1998;44:191-214.

[3] Salisbury C, Munro J. Walk-in centres in primary care: a review of the international literature. British Journal of General Practice 2002; 53-59.

[4] Tan S, Mays N. Impact of initiatives to improve access to, and choice of, primary and urgent care in England: A systematic review. Health Policy 2014; 118: 304-15.

[5] Carson D, Clay H, Stern R. Primary care and emergency departments. Report from the Primary Care Foundation, 2010.

[6] Monitor. Walk-in centre review: final report and recommendations. IRRES 02/2014 https://www.gov.uk/government/uploads/system/uploads/attachment data/file/283778/WalkInC entreFinalReportFeb14.pdf

[7] Mason S, Mountain G, Turner J, Arain M, Revue E, Weber EJ. Innovations to reduce demand and crowding in emergency care; a review study. Scandinavian Journal of Trauma, Resuscitation and Emergency Medicine 2014; 22: 55.

[8] Arain M, Campbell M, Nicholl J. Impact of a GP led walk-in centre on NHS emergency departments. Emergency Medicine, 2014, Online First: doi:10.1136/emermed-2013- 202410.

[9] Martin A, MacLeod C, Raza Naqvi SA. Models of care managing emergency department attendances. Evidence Adoption Centre, NHS, 2011.

[10] Chan CL, Lin W, Yang NP, Huang HT. The association between the availability of ambulatory care and non-emergency treatment in emergency medicine departments: a comprehensive and nationwide validation. Health Policy 2013;110:271-9.

[11] Belle Brown J, Sangster LM, Bouck T, Ostbye JM, Barnsley JM, Matthews $M$ et al. Walk-in Clinics in Ontario. An Atmosphere of Tension. Canadian Family Physician 2002;48:531-6.

[12] Szafran O, Bell NR. Use of Walk-in Clinics by rural and urban patients. Canadian Family Physician 2000;46:114-9. 
[13] Dalum K, Gravelle H, Santos R. Does access to Walk-in Centres affect attendance at accident and emergency departments? Unpublished 2013; paper presented at the HESG Meeting; Exeter.

[14] Salisbury C, Manku-Cott T, Moore L, Chalder M, Sharp D. Questionnaire survey of users of NHS walk-in centres: observational study. British Journal of General Practice 2002; 52:554-60.

[15] Buja A, Toffanin R, Rigon S, Sandonà P, Carraro D, Damiani G et al. Out-of-hours primary care services: Demands and patient referral patterns in a Veneto region (Italy) Local Health Authority. Health Policy 2015; 119:437-46.

[16] Tediosi F, Gabriele S, Longo F. Governing decentralization in health care under tough budget constraint: What can we learn from the Italian experience? Health Policy 2009;90:303-12.

[17] De Belvis AG, Ferrè F, Specchia ML, Valerio L, Fattore G. The financial crisis in Italy: Implications for the healthcare sector. Health Policy 2012;106(1):10-6.

[18] Fiorentini G, lezzi E, Lippi Bruni M, Ugolini C. Incentives in primary care and their impact on potentially avoidable hospital admissions. European Journal of Health Economics 2011;2(4):297309.

[19] Lega F, Mengoni A. Why non-urgent patients choose emergency over primary care services? Empirical evidence and managerial implications. Health Policy 2008;88(2-3):326-38.

[20] Fattore G, Forini F, Salvatore D, Tozzi V. Social network analysis in primary care: the impact of interactions on prescribing behaviour. Health Policy 2009;92:141-8.

[21] Visca M, Donatini A, Gini R, Federico B, Damiani G, Francesconi P et al. Group versus single handed primary care: A performance evaluation of the care delivered to chronic patients by Italian GPs. Health Policy 2013;113:188-98.

[22] Armeni P, Compagni A, Longo F. Multiprofessional Primary Care Units: What affects the Clinical performance of Italian general practitioners? Medical Care Research \& Review 2014; 71: 315.

[23] Cameron AC, Trivedi PK. Regression Analysis of Count Data. 2nd ed. Cambridge: Cambridge University Press; 2013.

[24] Hilbe JM. Negative Binomial Regression. Cambridge University Press 2011: second edition.

[25] Hausman JA. Specification Tests in Econometrics. Econometrica 1978;46(6):1251-71.

[26] Hausman JA, Hall B, Griliches Z. Econometric Models for Count Data with an Application to the Patents-R\&D Relationship. Econometrica 1984;52(4):909-38. 
[27] Dusheiko M, Gravelle $H$. The impact of Choose and Book on outpatient appointment nonattendances. Unpublished 2012; paper presented at the HESG Meeting, Aix-en-Provence.

[28] Allison P, Waterman R. Fixed effects negative binomial regression models. Sociological Methodology 2002;32:247-65.

[29] Guimaraes P. The fixed effects negative binomial model revisited. Economics Letters 2008;99:63-6.

[30] Cameron AC, Trivedi PK. Count Panel Data. In B. Baltagi ed. Oxford Handbook of Panel Data 2015; Oxford University Press: 233-56.

[31] Greenland S, Robins J. Ecological studies - Biases and misconceptions and counter-examples. American Journal of Epidemiology 1994; 139:747-60.

[32] Greenland S. Ecological versus individual-level sources of bias in ecologic estimates od contextual health effects. International Journal of Epidemiology 2001; 30:1343-50. 
Table 1- WiC's Workload: distribution of visits across times of the day and age composition of WiC's users.

\begin{tabular}{|c|c|c|c|c|c|c|}
\hline TOTAL VISITS WiC & 2007 & 2008 & 2009 & 2010 & 2007-2010 & Total \\
\hline Total & 23637 & 24850 & 23914 & 23583 & 95984 & 95984 \\
\hline TIME OF THE DAY & 2007 & 2008 & 2009 & 2010 & 2007-2010 & Total \\
\hline 8am-12am & $43 \%$ & $44 \%$ & $43 \%$ & $43 \%$ & $43 \%$ & 41347 \\
\hline $12 \mathrm{am}-4 \mathrm{pm}$ & $28 \%$ & $28 \%$ & $28 \%$ & $28 \%$ & $28 \%$ & 27024 \\
\hline $4 p m-8 p m$ & $29 \%$ & $27 \%$ & $29 \%$ & $30 \%$ & $29 \%$ & 27613 \\
\hline Total & $100 \%$ & $100 \%$ & $100 \%$ & $100 \%$ & $100 \%$ & 95984 \\
\hline AGE CLASS & 2007 & 2008 & 2009 & 2010 & 2007-2010 & Total \\
\hline Not available & $0 \%$ & $0 \%$ & $0 \%$ & $0 \%$ & $0 \%$ & 120 \\
\hline$<15$ & $2 \%$ & $2 \%$ & $3 \%$ & $4 \%$ & $3 \%$ & 2817 \\
\hline $15-44$ & $57 \%$ & $55 \%$ & $52 \%$ & $51 \%$ & $54 \%$ & 51624 \\
\hline $45-64$ & $23 \%$ & $24 \%$ & $25 \%$ & $25 \%$ & $24 \%$ & 23241 \\
\hline $65-74$ & $10 \%$ & $10 \%$ & $11 \%$ & $11 \%$ & $10 \%$ & 9953 \\
\hline Over 75 & $8 \%$ & $8 \%$ & $9 \%$ & $9 \%$ & $9 \%$ & 8229 \\
\hline Total & $100 \%$ & $100 \%$ & $100 \%$ & $100 \%$ & $100 \%$ & 95984 \\
\hline
\end{tabular}


Table 2 - Descriptive statistics

\begin{tabular}{|c|c|c|c|}
\hline VARIABLE & DEFINITION & Mean & SD \\
\hline WiC visits & Number of visits to the WiC per GP & 101.886 & 43.19 \\
\hline WiC visits $8 a m-12 a m$ & Number of visits to the WiC per GP in the morning & 45.553 & 19.75 \\
\hline WiC visits $12 \mathrm{am}-4 \mathrm{pm}$ & Number of visits to the WiC per GP in the early afternoon & 28.270 & 12.48 \\
\hline WiC visits $4 p m-8 p m$ & Number of visits to the WiC per GP in the late afternoon & 29.005 & 13.32 \\
\hline WiC visits $15-44$ & Number of visits to the WiC per GP for the group aged $15-44$ & 49.917 & 23.67 \\
\hline WiC visits $45-64$ & Number of visits to the WiC per GP for the group aged $45-64$ & 27.813 & 12.87 \\
\hline WiC visits $65-74$ & Number of visits to the WiC per GP for the group aged $65-74$ & 12.966 & 7.90 \\
\hline WiC visits Over 75 & Number of visits to the WiC per GP for the group aged $>75$ & 11.277 & 7.43 \\
\hline ED'visits & Number of visits to the ED per GP & 214.67 & 72.88 \\
\hline GP Male & $=1$ if $\mathrm{GP}$ is male & 0.79 & 0.41 \\
\hline GP seniority & Years of activity within the NHS & 21.12 & 8.41 \\
\hline GP Coordinator & $=1$ if $\mathrm{GP}$ has a coordination role & 0.83 & 0.38 \\
\hline Associated GP & $=1$ if GP works in a network or in a group & 0.81 & 0.39 \\
\hline Nursing staff & $=1$ if the practice avails of a nurse & 0.27 & 0.44 \\
\hline Extended opening hours $10-12$ & $=1$ if the practice extends opening hours $>9$ hours per day & 0.26 & 0.44 \\
\hline Adherence to local programs & $=1$ if GP participates in local programs & 0.75 & 0.43 \\
\hline List size & $=$ no. of patients enrolled in the GP list & 1240.49 & 355.98 \\
\hline Age group 15-44 (\% list) & $\%$ of patients aged $15-44$ in the GP list & 43.9 & 8.43 \\
\hline Age group 45-64 (\% list) & $\%$ of patients aged $45-64$ in the GP list & 29.88 & 4.18 \\
\hline Age group 65-74 (\% list) & $\%$ of patients aged $65-74$ in the GP list & 12.52 & 3.13 \\
\hline Age group over 75 (\% list) & $\%$ of patients aged over 75 in the GP list & 0.14 & 0.05 \\
\hline Male patients (\% list) & $\%$ of male patients in the GP list & 46.85 & 4.21 \\
\hline Foreign patients (\% list) & $\%$ of foreign patients in the list & 8.07 & 6.83 \\
\hline Observations & & 589 & \\
\hline
\end{tabular}




\begin{tabular}{|c|c|c|c|c|c|c|}
\hline No. of visits to the WiC for GP & $\begin{array}{r}\text { Coefficient } \\
\text { (SD) }\end{array}$ & $p$ value & IRR & $\begin{array}{r}\text { Coefficient } \\
\text { (SD) }\end{array}$ & p value & IRR \\
\hline ED'visits & & & & $\begin{array}{r}-0.00079 \\
(0.000)\end{array}$ & 0.017 & 0.99921 \\
\hline GP Male & $\begin{array}{r}0.27676 \\
(0.320)\end{array}$ & 0.388 & 1.31885 & $\begin{array}{r}0.13380 \\
(0.343)\end{array}$ & 0.696 & 1.14317 \\
\hline $\begin{array}{l}\text { GP seniority } \\
\text { GP Coordinator }\end{array}$ & $\begin{array}{r}0.06427 \\
(0.020)\end{array}$ & 0.001 & 1.06638 & $\begin{array}{r}0.05022 \\
(0.021)\end{array}$ & 0.017 & 1.05150 \\
\hline $\begin{array}{l}\text { Associated GP } \\
\text { Nursing staff }\end{array}$ & $\begin{array}{r}-0.0266 \\
(0.047)\end{array}$ & 0.572 & 0.97377 & $\begin{array}{r}-0.02100 \\
(0.046)\end{array}$ & 0.652 & 0.97922 \\
\hline $\begin{array}{l}\text { Extended opening hours } 10-12 \\
\text { Adherence to local programs }\end{array}$ & $\begin{array}{r}-0.08132 \\
(0.026)\end{array}$ & 0.002 & 0.92190 & $\begin{array}{r}-0.08118 \\
(0.026)\end{array}$ & 0.002 & 0.92203 \\
\hline Age group $15-44$ (\% list) & $\begin{array}{r}0.03414 \\
(0.009)\end{array}$ & 0.000 & 1.03473 & $\begin{array}{r}0.03679 \\
(0.009)\end{array}$ & 0.000 & 1.03747 \\
\hline $\begin{array}{l}\text { Age group } 45-64 \text { (\% list) } \\
\text { Age group } 65-74 \text { (\% list) } \\
\text { Male patients ( } \% \text { list) }\end{array}$ & $\begin{array}{r}0.00745 \\
(0.010)\end{array}$ & 0.451 & 1.00747 & $\begin{array}{r}0.00698 \\
(0.010)\end{array}$ & 0.480 & 1.00701 \\
\hline Foreign patients (\% list) & $\begin{array}{r}-0.01671 \\
(0.008)\end{array}$ & 0.034 & 0.98342 & $\begin{array}{r}-0.01892 \\
(0.008)\end{array}$ & 0.016 & 0.98126 \\
\hline Year 2008 & $\begin{array}{r}0.02866 \\
(0.030)\end{array}$ & 0.342 & 1.02907 & $\begin{array}{r}0.05704 \\
(0.032)\end{array}$ & 0.080 & 1.05870 \\
\hline Year 2009 & $\begin{array}{r}-0.05934 \\
(0.051)\end{array}$ & 0.242 & 0.94239 & $\begin{array}{r}-0.00159 \\
(0.057)\end{array}$ & 0.978 & 0.99841 \\
\hline Year 2010 & $\begin{array}{r}-0.13410 \\
(0.072)\end{array}$ & 0.063 & 0.87450 & $\begin{array}{r}-0.07699 \\
(0.077)\end{array}$ & 0.316 & 0.92590 \\
\hline Constant & $\begin{array}{r}-5.33936 \\
(0.605)\end{array}$ & 0.000 & 0.00480 & $\begin{array}{r}-4.88026 \\
(0.634)\end{array}$ & 0.000 & 0.00759 \\
\hline Ln List size (exposure) & 1 & & 1 & 1 & & 1 \\
\hline
\end{tabular}


Table 4 - FE estimates for distribution of visits across times of the day.

\begin{tabular}{|c|c|c|c|c|c|c|c|c|c|}
\hline \multirow[b]{2}{*}{$\begin{array}{l}\text { No. of visits to the WiC } \\
\text { for GP }\end{array}$} & \multicolumn{3}{|c|}{ 8am-12am } & \multicolumn{3}{|c|}{$12 \mathrm{am}-4 \mathrm{pm}$} & \multicolumn{3}{|c|}{$4 p m-8 p m$} \\
\hline & $\begin{array}{r}\text { Coefficient } \\
\text { (SD) }\end{array}$ & $\begin{array}{r}p \\
\text { value }\end{array}$ & IRR & $\begin{array}{c}\text { Coefficient } \\
\text { (SD) }\end{array}$ & $\begin{array}{r}p \\
\text { value }\end{array}$ & IRR & $\begin{array}{r}\text { Coefficient } \\
\text { (SD) }\end{array}$ & $\begin{array}{r}p \\
\text { value }\end{array}$ & IRR \\
\hline GP Male & $\begin{array}{r}0.22531 \\
(0.450)\end{array}$ & 0.616 & 1.25272 & $\begin{array}{r}1.34674 \\
(0.574)\end{array}$ & 0.019 & 3.84487 & $\begin{array}{r}0.48112 \\
(0.422)\end{array}$ & 0.254 & 1.61789 \\
\hline GP seniority & $\begin{array}{r}0.03420 \\
(0.027)\end{array}$ & 0.205 & 1.03479 & & & & & & \\
\hline GP Coordinator & & & & & & & $\begin{array}{r}-0.05714 \\
(0.042)\end{array}$ & 0.176 & 0.94446 \\
\hline Associated GP & $\begin{array}{r}-0.02835 \\
(0.062)\end{array}$ & 0.646 & 0.97205 & & & & & & \\
\hline Nursing staff & $\begin{array}{r}-0.08616 \\
(0.059)\end{array}$ & 0.143 & 0.91744 & & & & $\begin{array}{r}-0.13613 \\
(0.073)\end{array}$ & 0.063 & 0.87272 \\
\hline Extended opening hours & -0.15214 & & & & & & -0.04475 & & \\
\hline $\begin{array}{l}10-12 \\
\text { Adherence to local } \\
\text { programs }\end{array}$ & $(0.035)$ & 0.000 & 0.85886 & & & & $(0.045)$ & 0.324 & 0.95624 \\
\hline Age group $15-44$ (\% list) & $\begin{array}{r}0.03585 \\
(0.012)\end{array}$ & 0.003 & 1.03650 & $\begin{array}{r}0.04043 \\
(0.016)\end{array}$ & 0.010 & 1.04126 & $\begin{array}{r}0.03511 \\
(0.012)\end{array}$ & 0.004 & 1.03574 \\
\hline Age group 45-64 (\% list) & $\begin{array}{r}0.00764 \\
(0.013)\end{array}$ & 0.556 & 1.00767 & $\begin{array}{r}0.01223 \\
(0.019)\end{array}$ & 0.517 & 1.01230 & $\begin{array}{r}0.02147 \\
(0.016)\end{array}$ & 0.194 & 1.02170 \\
\hline $\begin{array}{l}\text { Age group } 65-74 \text { (\% list) } \\
\text { Male patients (\% list) }\end{array}$ & & & & $\begin{array}{r}-0.00883 \\
(0.022)\end{array}$ & 0.696 & 0.99120 & & & \\
\hline Foreign patients (\% list) & $\begin{array}{r}-0.02126 \\
(0.010)\end{array}$ & 0.040 & 0.97896 & & & & & & \\
\hline Year 2008 & $\begin{array}{r}0.10064 \\
(0.041)\end{array}$ & 0.014 & 1.10587 & $\begin{array}{r}0.08281 \\
(0.026)\end{array}$ & 0.001 & 1.08634 & $\begin{array}{r}-0.00733 \\
(0.033)\end{array}$ & 0.825 & 0.99270 \\
\hline Year 2009 & $\begin{array}{r}0.02969 \\
(0.068)\end{array}$ & 0.664 & 1.03013 & $\begin{array}{r}0.01712 \\
(0.028)\end{array}$ & 0.538 & 1.01727 & $\begin{array}{r}-0.00188 \\
(0.034)\end{array}$ & 0.956 & 0.99812 \\
\hline Year 2010 & $\begin{array}{r}-0.02583 \\
(0.98)\end{array}$ & 0.793 & 0.97450 & $\begin{array}{r}-0.01085 \\
(0.032)\end{array}$ & 0.736 & 0.98920 & $\begin{array}{r}-0.02299 \\
(0.039)\end{array}$ & 0.553 & 0.97727 \\
\hline Constant & $\begin{array}{r}-4.91041 \\
(0.79)\end{array}$ & 0.000 & 0.00737 & $\begin{array}{r}-5.50731 \\
(1.392)\end{array}$ & 0.000 & 0.00406 & $\begin{array}{r}-5.51300 \\
(0.919)\end{array}$ & 0.000 & 0.00403 \\
\hline Ln (list size) (exposure) & 1 & & 1 & 1 & & 1 & 1 & & 1 \\
\hline
\end{tabular}


Table 5 - FE estimates for age composition of WiC's users.

\begin{tabular}{|c|c|c|c|c|c|c|}
\hline \multirow{2}{*}{ No. of visits to the WiC for GP } & \multicolumn{3}{|c|}{ Age group 15-44 } & \multicolumn{3}{|c|}{ Age group 45-64 } \\
\hline & $\begin{array}{r}\text { Coefficient } \\
\text { (SD) }\end{array}$ & p value & IRR & $\begin{array}{c}\text { Coefficient } \\
\text { (SD) }\end{array}$ & p value & IRR \\
\hline GP Male & & & & $\begin{array}{r}1.71790 \\
(0.557)\end{array}$ & 0.002 & 5.57280 \\
\hline GP seniority & $\begin{array}{r}0.04264 \\
(0.018)\end{array}$ & 0.018 & 1.04357 & & & \\
\hline GP Coordinator & $\begin{array}{r}-0.06570 \\
(0.035)\end{array}$ & 0.065 & 0.93641 & & & \\
\hline Associated GP & $\begin{array}{r}-0.10661 \\
(0.063)\end{array}$ & 0.093 & 0.89888 & & & \\
\hline Nursing staff & $\begin{array}{r}-0.05578 \\
(0.062)\end{array}$ & 0.368 & 0.9364 & & & \\
\hline Extended opening hours $10-12$ & $\begin{array}{r}-0.09908 \\
(0.038)\end{array}$ & 0.009 & 0.90567 & $\begin{array}{r}-0.12094 \\
(0.043)\end{array}$ & 0.005 & 0.88609 \\
\hline Adherence to local programs & & & & & & \\
\hline Male patients (\% list) & & & & & & \\
\hline Foreign patients (\% list) & $\begin{array}{r}-0.00156 \\
(0.007)\end{array}$ & 0.833 & 0.99844 & & & \\
\hline Year 2008 & $\begin{array}{r}-0.01451 \\
(0.033)\end{array}$ & 0.662 & 0.98559 & $\begin{array}{r}0.12986 \\
(0.031)\end{array}$ & 0.000 & 1.13867 \\
\hline Year 2009 & $\begin{array}{r}-0.12549 \\
(0.048)\end{array}$ & 0.009 & 0.88206 & $\begin{array}{r}0.07470 \\
(0.031)\end{array}$ & 0.016 & 1.07756 \\
\hline Year 2010 & $\begin{array}{r}-0.19399 \\
(0.066)\end{array}$ & 0.003 & 0.82366 & $\begin{array}{r}0.00564 \\
(0.031)\end{array}$ & 0.858 & 1.00565 \\
\hline Constant & $\begin{array}{r}-2.80464 \\
(0.352)\end{array}$ & 0.000 & 0.06052 & $\begin{array}{r}-2.63461 \\
(0.246)\end{array}$ & 0.000 & 0.07175 \\
\hline Ln (age) (exposure) & 1 & & 1 & 1 & & 1 \\
\hline
\end{tabular}

